Letter to the editor

\section{Spinal congenital dermal sinus associated with upper thoracic meningocele}

To THE EDITOR: I read with great interest the article by Dr. Kara (Kara NN: Spinal congenital dermal sinus associated with upper thoracic meningocele. Case report. Neurosurg Focus 15 (1):Clinical Pearl 2, 2003).

\section{Abstract}

The congenital dermal sinus is an abnormal epithelium-lined sinus tract between the skin surface and deeper tissues. It occurs during neurulation when the neural groove closes to form the neural tube on Day 26 of gestation and results from a failure of neuroectoderm to separate from the cutaneous ectoderm. The most frequent location is the lumbosacral area; an upper thoracic location is quite rare.

This 37-year-old man presented with headache and numbness in both arms. No specific neurological findings were observed. Physical examination revealed a dimple at T-2. Radiography and magnetic resonance imaging of the thoracic spine revealed spina bifida at T1-3, a meningocele, and a dermal sinus tract complex. The treatment approach and outcome in this unusual case are presented.

I was proud to see another publication originate from the city where I live. The author has nicely documented his unique case of an adult with dermal sinus tract associated with meningocele; however, on careful inspection of the paper there are some deficiencies that I consider to be important.

1) As the author stated, thoracic dermal sinus tracts are unusual focal nondisjunction anomalies resulting from incomplete separation of neuroectoderm from cutaneous ectoderm, and a review of the world literature to date reveals 32 thoracic cases. ${ }^{1,2,5}$ I believe this should be pointed out for the sake of completeness. Results of a neurological examination are reported to be normal in children, but there is more chance of neurological deficit as patient age increases. ${ }^{5}$ For this reason, it seems that the author's claim that adults are generally asymptomatic is not true, in particular, the symptomatic case featured in the article itself.

2) In Fig. 2 in the article, there is no doubt that the axial magnetic resonance image is $T_{2}$-weighted, not $T_{1}$-weighted. Moreover, the statement " . . at the $\mathrm{T}_{2}$-weighted level" may create confusion and/or a misunderstanding. In fact, I think that the exact site of the termination point of the sinus tract coursing obliquely through the subcutaneous tissues in this case should be identified as the T- 3 level instead of T-2, where it attaches the intradural area with the meningocele sac in the midline, as clearly demonstrated in Figs. 2 and 3. As Barkovich, et al., ${ }^{3}$ have pointed out, I certainly think that it is important to know that the dermatome level of the sinus opening correlates with the metameric level of the spinal cord where it attaches.

3) Some of the information given in the Abstract is not included in the rest of the paper. In fact, this is contrary to the notion that the abstract in a scientific journal should give a very short summary of the main contents of the entire work. ${ }^{4}$

4) Last, I call your attention to many significant omissions in the article given that an author bears the responsibility of keeping abreast of related medical information. This lack is reflected by uncited historical studies of McIntosh, et al., ${ }^{6}$ and Powell, et al. ${ }^{7}$ It would be worthwhile to refer to these studies, even though case reports in the Journal of Neurosurgery should be brief and avoid an extensive review of the literature. Indeed, I think that a few additional papers in the reference list should be tolerated by the Editorial Board of the Journal, because reference to original studies is an important issue in scientific papers. In my opinion, another significant omission is a citation for the reference in which the reader can find information on Verebely, who first described this dermal sinus in 1913.

Mehmet Turgut, M.D. Adnan Menderes University Hospital, Aydın, Turkey

\section{References}

1. Ackerman LL, Menezes AH, Follett KA: Cervical and thoracic dermal sinus tracts. A case series and review of the literature. Pediatr Neurosurg 37:137-147, 2002

2. Arslantas A, Cosan TE, Güner A, et al: Dermal sinus tract, split cord malformation, and meningocele associated with lumbosacral lipoma. 29th Annual Meeting Poster Abstracts. The International Society for Pediatric Neurosurgery. (http:// www.ispn.org/Meetings/Aalborg/Poster03.htm) [Accessed 4 June 2004]

3. Barkovich AJ, Edwards M, Cogen PH: MR evaluation of spinal dermal sinus tracts in children. AJNR 12:123-129, 1991

4. Haynes RB, Mulrow CD, Huth EJ, et al: More informative abstracts revisited. Ann Intern Med 113:69-76, 1990

5. Jindal A, Mahapatra AK: Spinal congenital dermal sinus: an experience of 23 cases over 7 years. Neurol India 49:243-246, 2001

6. McIntosh R, Merritt KK, Richards MR, et al: The incidence of congenital malformations: a study of 5, 964 pregnancies. Pediatrics 14:505-522, 1954

7. Powell KR, Cherry JD, Hougen TJ, et al: A prospective search for congenital dermal abnormalities of the craniospinal axis. J Pediatr 87:744-750, 1975 